\title{
Atherogenic Dyslipidemia Remission 1 Year After Bariatric Surgery
}

Climent $\mathrm{E}^{\star}$, Benaiges D, Pedro-Botet J, Flores JA, Ramon-Moros JM, Villatoro M, Fontané L, Chillarón JJ, Goday A.

\section{INTRODUCTION}

Residual cardiovascular risk in obese patients is due, at least in part, to atherogenic dyslipidemia $(A D)$, characterised by low high-density lipoprotein (HDL) cholesterol levels, hypertriglyceridemia and an increased proportion of small and dense LDL particles [1,2]. Current clinical guidelines do not fully address $A D$ as their recommendations are mainly based on LDL cholesterol goals [3] or statin therapy [4] and it is therefore a condition that is frequently underdiagnosed, undertreated and undercontrolled $[5,6]$. On the other hand, bariatric surgery (BS) is known to be an effective treatment for severe obesity and its comorbidities, which in turn produces a significant reduction in cardiovascular risk [7]. In this respect, previous studies, mostly in the short term after BS, have reported a type 2 diabetes mellitus remission rate of $70-80 \%[7,8]$ and $50-70 \%$ remission of hypertension $[7,9]$. Moreover, although it is known that BS improves lipid profile, with approximately $70 \%$ improvement in hypercholesterolemia $[10,11]$, no previous studies have focused on the impact of BS on AD separately. Thus, the aim of the present study was to analyse the remission rate of $A D 1$ year after $B S$. 


\section{METHODS}

A retrospective analysis of a non-randomised prospective cohort was conducted on severely-obese patients undergoing BS at the Hospital del Mar, Barcelona, from January 2005 to May 2014. Patients were between 18 and 55 years of age and met the 1991 BS criteria of the National Institutes of Health [12]. The indication for the type of surgical procedure (laparoscopic sleeve gastrectomy and laparoscopic Roux-en-Y gastric bypass) was based on clinical criteria and the consensus of the BS Unit. In this respect, laparoscopic sleeve gastrectomy was preferred in younger patients, in those with a body mass index of $35-40 \mathrm{~kg} / \mathrm{m}^{2}$, as a first-step treatment in cases with body mass index $>50 \mathrm{~kg} / \mathrm{m}^{2}$ (although given the positive laparoscopic sleeve gastrectomy outcomes none of these patients had to further undergo laparoscopic Roux-en-Y gastric bypass), and when drug malabsorption was to be avoided.

All patients were evaluated preoperatively and at 3,6 and 12 months after surgery. Lipid-lowering therapy was supervised by the endocrinologist of the BS Unit throughout the preoperative, in-hospital and follow-up periods. Protocol visits included measurements of weight, waist and hip circumferences, blood pressure, and laboratory tests for glucose, insulin, glycated haemoglobin, total cholesterol, HDL cholesterol and triglycerides.

All patients signed an informed consent for the procedure and the study. The Ethics Committee of our Institution approved the protocol in accordance with the ethical guidelines of the 1975 Declaration of Helsinki.

Body mass index was calculated as weight in kilograms divided by height in square metres and the percentage of excess weight loss was based on the excess 
weight compared to the weight corresponding to a body mass index of $25 \mathrm{~kg} / \mathrm{m}^{2}$ for each patient.

Total cholesterol and triglycerides were determined using enzymatic methods in a Cobas Mira automatic analyser (Baxter Diagnostics AG, Düdingen, Switzerland). HDL cholesterol was measured using separation by precipitation with phosphotungstic acid and magnesium chloride. Glucose was determined by the oxidase method. Glycated haemoglobin was quantified by chromatography (Biosystem, Barcelona, Spain). Insulin was measured by radioimmunoassay (Insulin kit, DPC, Los Angeles, CA, USA). Non-HDL cholesterol was calculated as total cholesterol minus HDL cholesterol. HOMA-IR index was estimated using the following formula: HOMA-IR = insulin $(\mathrm{mU} / \mathrm{ml}) \times$ fasting glucose $(\mathrm{mmol} / \mathrm{l}) / 22.5$ [13]. Atherogenic index of plasma was calculated as log [triglycerides (mmol/l) / HDL cholesterol $(\mathrm{mmol} / \mathrm{l})]$.

$A D$ was defined as triglycerides $\geq 1.71 \mathrm{mmol} / \mathrm{l}$ or treatment with fibrates and low $\mathrm{HDL}$ cholesterol $(<1.03 \mathrm{mmol} / /$ in men or $<1.3 \mathrm{mmol} / \mathrm{l}$ in women) [2]. AD remission was defined as triglycerides $<1.71 \mathrm{mmol} / \mathrm{l}$ without fibrate therapy and HDL cholesterol levels $\geq 1.03 \mathrm{mmol} / \mathrm{l}$ in men or $\geq 1.3 \mathrm{mmol} / \mathrm{l}$ in women. Criteria for hypertension diagnosis were current treatment with antihypertensive agents and/or systolic blood pressure $>140 \mathrm{~mm} \mathrm{Hg}$ and/or diastolic blood pressure $>90 \mathrm{mmHg}$ [14]. Type 2 diabetes mellitus was defined as two fasting plasma glucose values > $6.94 \mathrm{mmol} / \mathrm{l}$ or glycated haemoglobin $\geq 6.5 \%$ or treatment with non-insulin hypoglycaemic agents or insulin [15]. Hypercholesterolemia was defined as total cholesterol > $5.2 \mathrm{mmol} / \mathrm{l}$ or use of cholesterol-lowering drugs [16]. Metabolic syndrome was defined as waist circumference $>102 \mathrm{~cm}$ in men or $>88 \mathrm{~cm}$ in women, triglycerides $\geq 1.71 \mathrm{mmol} / \mathrm{l}$, $\mathrm{HDL}$ cholesterol $<1.03 \mathrm{mmol} / \mathrm{l}$ in men or $<1.3$ 
$\mathrm{mmol} / \mathrm{l}$ in women, blood pressure $\geq 130$ or $\geq 85 \mathrm{mmHg}$ and fasting glucose $\geq 6.1$ $\mathrm{mmol} / \mathrm{l}$. When 3 of the 5 characteristics were present, the diagnosis of metabolic syndrome could be made [17].

The laparoscopic Roux-en-Y gastric bypass technique consisted of a $150-\mathrm{cm}$ antecolic Roux limb with a 25-mm circular pouch-jejunostomy and exclusion of $50 \mathrm{~cm}$ of the proximal jejunum. In laparoscopic sleeve gastrectomy, longitudinal resection of the stomach from the angle of His to approximately $5 \mathrm{~cm}$ proximal to the pylorus was performed using a 35 French bougie inserted along the lesser curvature. The same team of surgeons performed all operations.

Data was expressed as mean \pm standard deviation for continuous variables and as percentages and frequencies for categorical variables. Student's t-test was performed to assess differences between two means. Chi-square or Fisher's exact tests were used to evaluate the degree of association between categorical variables. ANOVA models were used to study the evolution of continuous variables in each group and analyse differences between groups at each time point from baseline. A two-sided $p$ value $<0.05$ was considered statistically significant. Statistical analysis was made with SPSS (version 19.0 for Windows; SPSS, Chicago, IL). 


\section{RESULTS}

A total of 380 Caucasian patients underwent BS between 2005 and 2014; of these, 24 were lost during follow-up without mortality. Of the 356 patients who completed follow-up, 203 (57.0\%) underwent laparoscopic Roux-en-Y gastric bypass and $153(43.0 \%)$ laparoscopic sleeve gastrectomy. Eighty per cent were women with a median age of $44.3 \pm 8.7$ years and a body mass index of $44.1 \pm 5.1 \mathrm{Kg} / \mathrm{m}^{2}$. Thirtythree $(9.3 \%)$ patients were receiving treatment with statins alone, $3(0.8 \%)$ statins plus ezetimibe, $11(3.1 \%)$ fibrates and $3(0.8 \%)$ a combination of statins and fibrates. AD was present in $22.8 \%$ of the study cohort, hypercholesterolemia in $40.7 \%$, type 2 diabetes mellitus in $22.1 \%$, hypertension in $41.4 \%$, and the metabolic syndrome in $66.9 \%$. Patients with $A D$ were more frequently men, had a larger abdominal circumference and higher total cholesterol and non-HDL cholesterol concentrations. Furthermore, they also had a higher percentage of type 2 diabetes mellitus, hypertension, and the metabolic syndrome and were more frequently smokers (Table 1).

The percentage of excess weight loss was progressive 1 year after BS, with no differences between patients with and without AD (Figure 1).

The $A D$ remission rate after surgery was $74.1 \%$ at 3 months, $90.1 \%$ at 6 months and $96.3 \%$ at 1 year. Focusing on the 2 different surgical techniques, 12 months AD remission was $98.0 \%$ after sleeve gastrectomy and 100\% after Roux-en$Y$ gastric bypass $(p=0.078)$. Moreover, no patients without $A D$ at baseline developed this atherogenic profile 1 year after surgery. With respect to AD components, HDL cholesterol rose progressively from 6 months onwards after BS in both groups, being significantly higher in the $A D$ group with respect to the group without $A D(47.6 \pm$ $31.6 \%$ versus $24.1 \pm 23.2 \%$, respectively; $p<0.001$ ) (Figure $2 A$ ). Triglyceride levels 
also showed an improvement that was already evident at 3 months in both groups but with a greater significant decrease in the AD group throughout all follow-up (49.3 $\pm 21.3 \%$ versus $21.2 \pm 53.0 \%$, respectively; $p<0.001$ ) (Figure 2B). Regarding lipidlowering therapy prior to surgery, fibrates and ezetimibe could be withdrawn in all patients after BS and statins in $69.4 \%$.

With respect to non-HDL cholesterol, $78.8 \%$ in the $A D$ group and $58.7 \%$ in the non-AD group presented levels $>3.3 \mathrm{mmol} / \mathrm{l}$ at baseline, decreasing after $\mathrm{BS}$ to $43.2 \%$ and $28 \%$, respectively. Non-HDL cholesterol levels $>2.6 \mathrm{mmol} / \mathrm{l}$ were present at baseline in $98.8 \%$ of patients in the $A D$ group and $88.0 \%$ in the non-AD group, dropping at 1 year after BS to $76.5 \%$ and $66.5 \%$, respectively.

Atherogenic index of plasma had decreased in both groups 1 year after BS, with a greater decline in the AD group compared to the group without the atherogenic profile (Figure 2C). Finally, insulin resistance also dropped in both groups, with the greatest decrease in the first 3 months in the group with AD (Figure 2D). 


\section{DISCUSSION}

The present study, the first to focus on $A D$ in severely-obese patients undergoing BS, shows that approximately $20 \%$ of these patients meet AD criteria prior to surgery, and that almost all are in complete remission 1 year after surgery.

The prevalence of $A D$ in general Spanish population is $4.9 \%$ [18]. Moreover, 1 of every 6 patients treated in lipid units have AD: the prevalence of this condition is associated with overweight/obesity, diabetes, previous myocardial infarction or heart failure and lack of lipid-lowering therapy [19]. In our study, the increased prevalence was probably due to the fact that a strong link exists between abdominal obesity and $A D$. Despite this close relationship, data on prevalence of $A D$ before surgery in cohorts of BS patients are lacking. Previous studies on this group of patients have reported on HDL and triglyceride levels separately, with a prevalence of hypertriglyceridemia close to $25 \%$ and $40 \%$ with low HDL levels before surgery $[20,21]$.

In this study, a $52 \%$ decrease in triglycerides and a $44 \%$ increase in HDL cholesterol levels was observed in the group with $A D$ at 12 months. These results concur with those of previous BS studies, which reported a $30-63 \%$ decrease and a 12-39\% increase in triglyceride and HDL cholesterol levels, respectively, in the short term after surgery $[22,23]$.

Some findings of the present study should be highlighted. First, triglyceride concentrations showed a greater decrease from 3 months onwards after BS and before major weight loss occurred. This suggests that hypertriglyceridemia improvement does not depend only on weight loss and that other factors are involved. HOMA-IR showed a parallel decrease to triglycerides (with the biggest drop in the first 3 months), and may therefore be linked to $A D$ improvement as they share 
a physiopathological basis [11]. In fact, a preceding study by our group revealed the main predictors of triglyceride reduction to be HOMA-IR decrease and baseline triglycerides [20].

With respect to HDL cholesterol, levels began to rise at 6 months onwards after surgery, coinciding with the achievement of significant weight loss. This feature, together with the similar results reported regardless of surgical technique $[24,25]$, may probably account for $\mathrm{HDL}$ improvement being related more to weight loss compared to hypertriglyceridemia.

Atherogenic index of plasma is a logarithmic ratio composed of triglycerides (numerator) and HDL cholesterol (denominator) [26]. This ratio presents a positive correlation with the degree of $\mathrm{HDL}$ esterification, a negative correlation with $\mathrm{LDL}$ particle size and is related to insulin resistance, thereby predicting an increase in atherogenic plasma risk [27]. In this study, atherogenic index of plasma showed the greatest decline at 3 months onwards after surgery in the AD group concurrently with HOMA-IR evolution. On the same lines, Garcia-Marirrodriga et al [28] found the reduction in the atherogenic index of plasma to be related to $A D$ and HOMA-IR improvement.

Although we did not compare the different surgical techniques used, preceding studies found that the major components of $A D$ improved similarly with both techniques $[20,29]$. This differed from LDL cholesterol, which showed a greater improvement with malabsorptive procedures [30].

Since almost all patients show complete AD remission at 1 year after $B S$ in the present study, and a significant number achieved non-HDL cholesterol goals, a decline in cardiovascular risk is therefore expected. A reduction in the number of cardiovascular events (HR 0.47) and cardiovascular deaths (HR 0.67) has been 
previously described in obese adults after BS in the Swedish Obese Subjects group [31].

Limitations of the study were mainly due to the low percentage of males in the study group, although it is important to emphasise that this ratio was similar to those of other bariatric surgery series [32]. Data on lifestyle habits such as diet and physical activity were not available. Finally, although LDL particle size and apolipoprotein B were not measured, the atherogenic index of plasma logarithm and non-HDL cholesterol were estimated.

In conclusion, among other metabolic effects, BS has benefits on the lipid profile, with complete remission of $A D$ being achieved at 1 year of follow-up in almost all patients. Weight loss appeared to have a greater impact on HDL cholesterol than on triglyceride improvement. Given the known refractoriness of $A D$ to lifestyle modifications and the paucity of clinical evidence on the effectiveness of pharmacological treatment with fibrates, BS could be considered a therapeutic approach for patients with morbid obesity and $A D$, although more long-term studies are required. 


\section{CONFLICT OF INTEREST DISCLOSURE:}

The authors declare that they have no conflict of interest

\section{ETHICAL APPROVAL:}

All procedures performed in studies involving human participants were in accordance

with the ethical standards of the institutional and/or national research committee and with the 1964 Helsinki declaration and its later amendments or comparable ethical standards.

\section{INFORMED CONSENT:}

Informed consent was obtained from all individual participants included in the study. 


\section{REFERENCES}

${ }^{1}$ Austin MA, King MC, Vranizan KM, Krauss RM. Atherogenic lipoprotein phenotype. A proposed genetic marker for coronary heart disease risk. Circulation 1990;82:495506.

${ }^{2}$ Grundy S. Small LDL, atherogenic dyslipidemia, and the metabolic syndrome. Circulation 1997;95:1-4.

${ }^{3}$ Piepoli MF, Hoes AW, Agewall S, Albus C, Brotons C, Catapano AL. 2016 European Guidelines on cardiovascular disease prevention in clinical practice: The Sixth Joint Task Force of the European Society of Cardiology and Other Societies on Cardiovascular Disease Prevention in Clinical Practice (constituted by representatives of 10 societies and by invited experts): Developed with the special contribution of the European Association for Cardiovascular Prevention \& Rehabilitation (EACPR). Eur Heart J 2016 May 23. pii: ehw106. [Epub ahead of print]

${ }^{4}$ Stone NJ, Robinson J, Lichtenstein AH, Bairey Merz CN, Blum CB, Eckel RH. 2013 ACC/AHA guidelines on the treatment of blood cholesterol to reduce atherosclerotic cardiovascular risk in adults: a report of the American College of Cardiology/American Heart Association Task Force on Practice Guidelines. J Am Coll Cardiol 2014;63:2889-934.

${ }^{5}$ Millán Núñez-Cortés J, Pedro-Botet J, Brea-Hernando Á, Díaz-Rodríguez Á, González-Santos P, Hernández-Mijares A, et al. Use of expert consensus to improve atherogenic dyslipidemia management. Rev Esp Cardiol 2014;67:36-44. 
${ }^{6}$ Pedro-Botet J, Mantilla-Morató T, Díaz-Rodríguez Á, Brea-Hernando Á, GonzálezSantos $\mathrm{P}$, Hernández-Mijares, et al. The role of atherogenic dyslipidaemia in clinical practice guidelines. Clin Investig Arterioscler 2016;28:65-70.

${ }^{7}$ Buchwald $\mathrm{H}$, Avidor $\mathrm{Y}$, Braunwald E, Jensen MD, Pories W, Fahrbach $\mathrm{K}$, et al. Bariatric surgery: a systematic review and meta-analysis. JAMA 2004;292:1724-37.

${ }^{8}$ Sjöström L, Lindroos A-K, Peltonen M, Torgerson J, Bouchard C, Carlsson B, et al. Swedish Obese Subjects Study Scientific Group. Lifestyle, diabetes, and cardiovascular risk factors 10 years after bariatric surgery. $N$ Engl $\mathrm{J}$ Med 2004;351:2683-93.

${ }^{9}$ Benaiges D, Sagué M, Flores-Le Roux JA, Pedro-Botet J, Ramón JM, Villatoro M, et al. Predictors of Hypertension Remission and Recurrence After Bariatric Surgery. Am J Hypertens 2016;29:653-9.

${ }^{10}$ Vidal J, lbarzabal A, Romero F, Delgado S, Momblán D, Flores L, et al. Type 2 diabetes mellitus and the metabolic syndrome following sleeve gastrectomy in severely obese subjects. Obes Surg 2008;18:1077-82.

${ }^{11}$ Carswell KA, Belgaumkar AP, Amiel SA, Patel AG. A Systematic Review and Meta-analysis of the Effect of Gastric Bypass Surgery on Plama Lipid Levels. Obes Surg 2016;26:834-55. 
${ }^{12}$ National Institutes of Health. Consensus Development Conference Draft Statement on Gastrointestinal Surgery for Severe Obesity. Obes Surg 1991;1:257-65.

${ }^{13}$ Matthews DR, Hosker JP, Rudenski AS, Naylor BA, Treacher DF, Turner RC. Homeostasis model assessment: insulin resistance and beta-cell function from fasting plasma glucose and insulin concentrations in man. Diabetologia $1985 ; 28: 412-9$.

${ }^{14}$ Chobanian AV, Bakris GL, Black HR, Cushman WC, Green LA, Izzo JL, et al. National Heart, Lung, and Blood Institute Joint National Committee on Prevention, Detection, Evaluation, and Treatment of High Blood Pressure, National High Blood Pressure Education Program Coordinating Committee. The Seventh Report of the Joint National Committee on Prevention, Detection, Evaluation, and Treatment of High Blood Pressure: the JNC 7 report. JAMA 2003;289:2560-72.

${ }^{15}$ Genuth S, Alberti KGMM, Bennett P, Buse J, Defronzo R, Kahn R, et al. Expert Committee on the Diagnosis and Classification of Diabetes Mellitus. Follow-up report on the diagnosis of diabetes mellitus. Diabetes Care 2003;26:3160-7.

${ }^{16}$ Brethauer SA, Kim J, Chaar M El, Papasavas P, Eisenberg D, Rogers A, et al. ASMBS Clinical Issues Committee. Standardized outcomes reporting in metabolic and bariatric surgery. Obes Surg 2015;25:587-606.

17 Grundy SM, Brewer HB, Cleeman JI, Smith SC, Lenfant C. American Heart Association, National Heart, Lung, and Blood Institute. Definition of metabolic 
syndrome: Report of the National Heart, Lung, and Blood Institute/American Heart Association conference on scientific issues related to definition. Circulation 2004;109:433-8.

${ }^{18}$ González-Juanatey JR, Millán J, Alegría E, Guijarro C, Lozano JV, Vitale GC. Prevalence and Characteristics of Lipid Abnormalities in Patients Treated With Statins in Primary and Secondary Prevention in Spain. DYSIS-Spain Study. Rev Española Cardiol (English Ed 2011);64:286-294.

${ }^{19}$ Pedro-Botet J, Flores-Le Roux JA, Mostaza JM, Pintó X, de la Cruz JJ, Banegas JR. Atherogenic dyslipidemia: prevalence and management in lipid clinics. Rev Clin Esp 2014;214:491-8.

${ }^{20}$ Benaiges D, Flores-Le-Roux JA, Pedro-Botet J, Ramon JM, Parri A, Villatoro M, et al. Impact of restrictive (sleeve gastrectomy) vs hybrid bariatric surgery (Roux-en-Y gastric bypass) on lipid profile. Obes Surg 2012;22:1268-75.

${ }^{21}$ Courcoulas AP, Christian NJ, Belle SH, Berk PD, Flum DR, Garcia L, et al. Longitudinal Assessment of Bariatric Surgery (LABS) Consortium. Weight change and health outcomes at 3 years after bariatric surgery among individuals with severe obesity. JAMA 2013;310:2416-25.

${ }^{22}$ Asztalos BF, Swarbrick MM, Schaefer EJ, Dallal GE, Horvath K V, Ai M, et al. Effects of weight loss, induced by gastric bypass surgery, on HDL remodeling in obese women. J Lipid Res 2010;51:2405-12. 
${ }^{23}$ Habib P, Scrocco JD, Terek M, Vanek V, Mikolich JR. Effects of bariatric surgery on inflammatory, functional and structural markers of coronary atherosclerosis. Am J Cardiol 2009;104:1251-5.

${ }^{24}$ Lee WJ, Chong K, Ser KH, Lee YC, Chen SC, Chen JC, et al. Gastric bypass vs sleeve gastrectomy for type 2 diabetes mellitus: a randomized controlled trial. Arch Surg 2011;146:143-8.

${ }^{25}$ Woelnerhanssen B, Peterli R, Steinert RE, Peters T, Borbély Y, Beglinger C. Effects of postbariatric surgery weight loss on adipokines and metabolic parameters: comparison of laparoscopic Roux-en-Y gastric bypass and laparoscopic sleeve gastrectomy-a prospective randomized trial. Surg Obes Relat Dis 2007;7:561-8.

${ }^{26}$ Mclaughlin T, Abbasi F, Cheal K, Chu J, Lamendola C, Reaven G. Use of Metabolic Markers To Identify Overweight Individuals Who Are Insulin Resistant. Ann Intern Medicine 2003;139:802-9.

${ }^{27}$ Millán J, Pintó X, Muñoz A, Zúñiga M, Rubiés-Prat J, Pallardo LF, et al. Lipoprotein ratios: Physiological significance and clinical usefulness in cardiovascular prevention. Vasc Health Risk Manag 2009;5:757-65.

${ }^{28}$ Garcia-Marirrodriga I, Amaya-Romero C, Ruiz-Diaz GP, Férnandez S, BallestaLópez C, Pou JM, et al. Evolution of lipid profiles after bariatric surgery. Obes Surg 2012;22:609-16. 
${ }^{29}$ Leyba JL, Aulestia SN, Llopis SN. Laparoscopic Roux-en-Y gastric bypass versus laparoscopic sleeve gastrectomy for the treatment of morbid obesity. A prospective study of 117 patients. Obes Surg 2011;21:212-6.

${ }^{30}$ Pihlajamäki J, Grönlund S, Simonen M, Käkelä P, Moilanen L, Pääkkönen M, et al. Cholesterol absorption decreases after Roux-en-Y gastric bypass but not after gastric banding. Metabolism 2010;59:866-72.

${ }^{31}$ Sjöström L, Peltonen M, Jacobson P, Sjöström CD, Karason K, Wedel H, et al. Bariatric surgery and long-term cardiovascular events. JAMA 2012;307:56-65.

${ }^{32}$ Berrington de Gonzalez A, Hartge P, Cerhan JR, Flint AJ, Hannan L, Maclnnis RJ, et al. Body-mass index and mortality among 1.46 million white adults. $N$ Engl J Med 2010;363:2211-9. 


\section{FIGURE LEGENDS}

Figure 1: Changes in percentage of excess weight loss during follow-up after the bariatric surgical procedure in patients with and without atherogenic dyslipidemia. Legend: *Differences between groups from baseline $(p<0.05)$; † Differences from baseline in subjects without atherogenic dyslipidemia $(p<0.05)$; $¥$ Differences from baseline in subjects with atherogenic dyslipidemia $(p<0.05)$.

Figure 2: Changes in HDL-cholesterol $(A)$, triglycerides $(B)$, atherogenic index (C), and HOMA-IR (D) during follow-up after the bariatric surgical procedure in patients with and without atherogenic dyslipidemia.

Legend: *Differences between groups from baseline $(p<0.05)$; † Differences from baseline in subjects without atherogenic dyslipidemia $(p<0.05)$; $¥$ Differences from baseline in subjects with atherogenic dyslipidemia $(p<0.05)$. 
Table 1. Clinical characteristics of severely-obese patients with and without atherogenic dyslipidemia.

\begin{tabular}{|l|l|l|l|}
\hline & $\begin{array}{l}\mathrm{AD} \\
\mathrm{n}=81\end{array}$ & $\begin{array}{l}\text { No AD } \\
\mathrm{n}=275\end{array}$ & $\mathrm{p}$ \\
\hline Women (\%) & $57(70.4)$ & $228(82.9)$ & 0.012 \\
\hline Age (years) & $44.7 \pm 9.3$ & $44.2 \pm 8.5$ & 0.624 \\
\hline BMI (kg/m) & $43.9 \pm 5.3$ & $44.1 \pm 5.0$ & 0.800 \\
\hline Abdominal circumference (cm) & $130.9 \pm 9.6$ & $127.3 \pm 12.8$ & 0.032 \\
\hline Type of surgery (\% of LRYGB) & $37(45.7)$ & $166(60.4)$ & 0.013 \\
\hline Total cholesterol (mmol/l) & $5.1 \pm 0.8$ & $4.9 \pm 0.9$ & 0.049 \\
\hline HDL cholesterol (mmol/l) & $1.0 \pm 0.2$ & $1.3 \pm 0.4$ & $<0.001$ \\
\hline Triglycerides (mmol/l) & $2.5 \pm 0.9$ & $1.2 \pm 0.4$ & $<0.001$ \\
\hline Non-HDL cholesterol (mmol/l) & $4.1 \pm 0.8$ & $3.6 \pm 0.9$ & $<0.001$ \\
\hline Hypercholesterolemia (\%) & $35(43.2)$ & $110(40.0)$ & 0.381 \\
\hline Type 2 diabetes mellitus (\%) & $35(43.2)$ & $44(16.0)$ & $<0.001$ \\
\hline Hypertension (\%) & $50(61.7)$ & $97(35.4)$ & $<0,001$ \\
\hline Metabolic syndrome (\%) & $81(100.0)$ & $157(57.1)$ & $<0.001$ \\
\hline Smokers (\%) & $30(37.0)$ & $72(26.4)$ & 0.044 \\
\hline
\end{tabular}

AD: atherogenic dyslipidemia. BMI: body mass index. LRYGB: laparoscopic Roux-en-Y gastric bypass. 